\title{
ASPECTOS JURÍDICOS E SOCIAIS DA CRIMINALIDADE JUVENIL: UMA ANÁLISE DE ESTATÍSTICAS
}

\author{
SOCIAL AND LEGAL ASPECTS OF JUVENILE CRIME: AN ANALYSIS OF \\ STATISTICS
}

\section{Resumo}

O fenômeno da violência é algo presente nas mais antigas sociedades, entretanto nas últimas décadas, fixam-se nesse cenário jovens menores de idade, demostrando uma enorme agressividade e desrespeito às regras legais e morais. Desse modo, o presente trabalho se propõe a discutir a criminalidade juvenil na cidade de Teresina, apresentando como objetivo geral a análise dos fatores que possivelmente possam motivar os adolescentes a adotar comportamentos agressivos, inserção e permanência no mundo do crime. A escolha do tema é de grande importância, pois o envolvimento de jovens com práticas ilícitas é um fenômeno de cunho social, político e familiar, vislumbrando a premissa de que a delinquência juvenil é um problema social multifatorial, que merece atenção de todos os segmentos sociais. Ademais o estudo, foi realizado por meio de uma pesquisa descritiva quantitativa de cunho bibliográfico, aliada a uma pesquisa de campo, por meio da coleta de dados disponibilizados pela Delegacia Geral da Polícia Civil do Estado do Piauí sobre as ocorrências criminais envolvendo menores de dezoito anos, entre os anos de 2009 a 2012 na capital piauiense.

Palavras-Chave: Criminalidade. Adolescente infrator. Medida socioeducativa

\begin{abstract}
The phenomenon of violence is something present in the earliest societies, though in recent decades, they set up this scenario underage youth, showing tremendous aggressiveness and disregard for the legal and moral rules. Thus, this paper aims to discuss juvenile crime in the city of Teresina, with the general objective of the analysis of the factors that could possibly motivate adolescents to adopt aggressive behavior, inclusion and permanence in the world of crime. The theme is of great importance, because the involvement of young people with illegal practices is a phenomenon of social, political and family, seeing the premise that juvenile delinquency is a social multifactorial problem that deserves attention from all segments of society. Furthermore the study was performed by means of a descriptive quantitative bibliographical, combined with field research, by collecting data made available by the Police General Civil Police of the state of Piauí on incidents involving criminal under eighteen between the years 2009 to 2012 in the capital of Piauí.
\end{abstract}

Key-Words: Criminality. Violator teenager. Socio- educational measure 


\section{INTRODUÇÃO}

A criminalidade é um problema de cunho social, econômico e político que se relaciona diretamente com a qualidade de vida de uma sociedade, especialmente no que se refere à delinquência juvenil, pois a presença de jovens no mundo do crime evidencia um meio social deficiente.

Tal situação gera muitas discussões no Brasil, seja em decorrência da inimputabilidade dos menores de dezoito anos, seja da brandura das medidas socioeducativas, quando comparadas à crueldade das infrações cometidas por menores infratores, vislumbrando um conflito relevante, pois, se por um lado, a sociedade tem o dever de evitar a perda dos adolescentes para a criminalidade, por outro, ela também não pode ficar refém de jovens violentos e transgressores que se escondem atrás de leis demasiadamente protecionistas.

Nesse contexto, o presente trabalho tem como objetivo geral, analisar a criminalidade juvenil na cidade de Teresina entre os anos de 2009 a 2012 e discutir os fatores que levam os adolescentes à prática de atos ilícitos, sua inserção e permanência na criminalidade.

Desse modo, a escolha do tema justifica-se pelo fato da criminalidade juvenil ser um fenômeno social, que envolve a participação da sociedade, do Estado e da família, uma vez que são os responsáveis pela tutela dos direitos das crianças e dos adolescentes, devendo propiciar condições para o pleno desenvolvimento desses sujeitos.

A realização deste estudo se deu por meio de uma pesquisa descritiva quantitativa de cunho bibliográfico sobre a criminalidade juvenil, aliada a uma pesquisa de campo realizada por meio da coleta de dados estatísticos disponibilizados pela Delegacia Geral da Polícia Civil do Estado do Piauí, especificamente, da Delegacia de Segurança e Proteção ao Menor DSPM (menor infrator) e Delegacia de Proteção à Criança e ao Adolescente - DPCA (menor vítima).

Assim, o estudo se reveste de grande contribuição, não somente para a comunidade acadêmica jurídica, mas para a sociedade em geral, pois discutir os possíveis fatores responsáveis pelo despertar da violência no jovem e sua inserção na criminalidade é uma maneira eficaz de buscar a solução para esse problema social que assola a convivência em sociedade. 


\section{LEGISLAÇÃO BRASILEIRA E O ADOLESCENTE INFRATOR}

A Constituição Federal de 1988, em seu artigo 227, trata da proteção integral à criança e ao adolescente, assegurando-lhes direitos que devem ser velados pela família, Estado e Sociedade até seu pleno desenvolvimento na vida adulta. Além da previsão constitucional, para melhor aplicação de tal prerrogativa, o legislador elaborou uma legislação especial no intuito de estabelecer as normas gerais e específicas de proteção à infância e à adolescência.

Dessa maneira, surge o Estatuto da Criança e do Adolescente através da Lei $\mathrm{n}^{\circ}$. 8.069/90, que passará a dispor sobre os direitos dos menores, estabelecendo um sistema de proteção integral e integrada. Assim, a doutrina de proteção integral aos menores, iniciada na Constituição de 1988, torna-se mais conhecida com a vigência do ECA, no qual, aqueles são caracterizados como indivíduos que não possuem o desenvolvimento pleno de suas potencialidades e, por isso, gozam de garantias fundamentais até a sua maioridade, conforme o caput do referido Estatuto:

\footnotetext{
Art. $3^{\circ}$ - A criança e o adolescente gozam de todos os direitos fundamentais inerentes à pessoa humana, sem prejuízo da proteção integral de que trata esta lei, assegurando - lhes, por lei ou por outros meios, todas as oportunidades e facilidades, a fim de lhes facultar o desenvolvimento físico, mental, moral, espiritual e social, em condições de liberdade e de dignidade. (LEI N 8.069/1990, BRASIL, 2011).
}

Para Cunha, Lépore e Rossato (2011, p. 81), o ECA é "um postulado normativo do interesse superior da criança, servindo como um norte para a aplicação dos princípios e regras referentes ao direito da criança e do adolescente, bem como um exame de razoabilidade quanto à aplicação de normas jurídicas"

De fato, é de suma importância a existência de garantias constitucionais no que, tange a proteção ao menor, todavia, o protecionismo legislativo causa discussões controversas quando se referem a adolescentes infratores, em especial, à garantia da inimputabilidade penal, pois o Código Penal Brasileiro dispõe em seu texto, especificamente no artigo 27, que “os menores de 18 anos são penalmente inimputáveis ficando sujeitos às normas estabelecidas na legislação especial".

Assim, os adolescentes que cometem atos infracionais são submetidos às medidas socioeducativas, elencadas no artigo 112 da Lei $n^{\circ} 8.069 / 90$, a saber: 
I - advertência;

II - obrigação de reparar o dano;

III - prestação de serviços à comunidade;

IV - liberdade assistida;

$\mathrm{V}$ - inserção em regime de semiliberdade;

VI - internação em estabelecimento educacional

VII - qualquer das medidas previstas no art. 101, I a VI

$\S 1 .^{\circ}$ A medida aplicada ao adolescente levará em conta a sua capacidade de cumprila, as circunstâncias, e a gravidade da infração.

§2. Em hipótese alguma e sob pretexto algum, será admitida a prestação de trabalho forçado.

§3. ${ }^{\circ}$ Os adolescentes portadores de doença ou deficiência mental receberão tratamento individual e especializado, em local adequado às suas condições.

Tais medidas socioeducativas possuem uma abrangência pedagógica caracterizada pela utilização de diferenciados recursos que, de acordo com Cunha, Lépore e Rossato (2011, p.331), "objetivam suprir o déficit apurado e a ressocialização do adolescente".

D’Andrea (2009, p. 90) afirma que "as medidas socioeducativas visam à reeducação e ressocialização do adolescente que houver cometido ato infracional, sendo mais leve ou rigorosa, dependendo da gravidade do ato e das condições pessoais do menor", ou seja, a intenção é reprimir a conduta infracional e reeducar.

O fato é que todas as medidas socioeducativas têm conteúdo pedagógico e caráter sancionador, entretanto alguns segmentos da sociedade consideram-nas brandas, pois rotineiramente é comum cenas de adolescentes participando de crimes como homicídios, roubos, tráfico, assaltos e outros tantos, de forma que o tema provoca sempre muitas discussões, dentre as quais o aumento da maioridade penal, medidas socioeducativas mais severas, sistemas prisionais mais rígidos, ou seja, sanções que sejam correspondentes com a gravidade do delito cometido.

Nesse contexto, surge uma divisão de opiniões, pois autores como Cunha, Lépore e Rossato (2011) afirmam que o fator econômico e social, o desemprego, a desagregação familiar, o abandono escolar e o fácil acesso a drogas podem ser as possíveis causas responsáveis pela delinquência juvenil e que o encarceramento não resolveria o problema. Em contrapartida, Adorno, Bordini e Lima (1999) afirmam que, a associação entre adolescência e a criminalidade não consiste em uma inquietação exclusivamente própria de sociedades com acentuadas desigualdades sociais ou desajustes familiares, ao contrário, é cada vez mais comum a imagem de jovens de classe média associadas à irresponsabilidade, liberdade incontrolável, permissividade, inclusive sexual, negligência, imaturidade e impunidade, instalando um pânico social. 
Dessa forma, o problema da violência associado à adolescência assume uma controvérsia, na qual de um lado estão os defensores dos Direitos Humanos que defendem a premissa de que os adolescentes cometem crimes por razões sociais e psicológicas, do outro lado estão as famílias vítimas de crimes cometidos por menores, que argumentam que a agressividade é inerente ao caráter do adolescente infrator e a falta de punição, pois as sanções previstas na legislação especial, nem sempre, correspondem à gravidade do ato infracional cometido.

Desse modo, para compreender o desencadeamento do comportamento delinquente dos adolescentes, é preciso analisar uma série de causas, a fim de identificar a origem dessa agressividade, buscando estudar o fenômeno da delinquência juvenil e as possíveis soluções para sua repressão, afinal não se pode consentir o abandono da juventude ao acaso de sua própria sorte e nem tão pouco exigir que a sociedade se conforme com tanta violência e agressividade.

\section{FATORES DO AUMENTO DA CRIMINALIDADE ENTRE JOVENS}

Existem muitas teorias para a origem da criminalidade, cada uma se aplica para definir esta ou aquela situação, mas nenhuma irá definir o berço de todos os delitos. Isto ocorre porque o crime é um conceito amplo e complexo, que envolve muitos fatores, de forma que não há uma teoria geral da criminalidade, pois os crimes são distintos por terem causas e motivações diversas.

Para Neis (2008), a incidência de crimes está vinculada a muitos fatores, de maneira que, afirmar por si só, que esses fatores conduzem à prática delituosa, seria um equívoco, pois o crime é resultante de múltiplas situações e não produto de uma única causa.

Assim, Panucci (2004) afirma que a criminalidade pode ter causas multifatoriais, pessoais e externas, sendo as causas multifatoriais, ligadas à impunidade ou a sanções brandas; as causas pessoais, ligadas ao comportamento humano, dado por fatores instintivos ou psicológicos, representados pelos transtornos de personalidade e as causas externas ligadas à influência do meio sob o indivíduo, como conflitos familiares, drogas e exclusão social.

Logo, as causas da criminalidade e da violência entre jovens é um assunto que remete a muitas indagações e debates, pois os motivos que levam um adolescente ao cometimento de delitos podem estar ligados a vários fatores, como influência individual 
relacionada à biografia pessoal, inserção em grupos, conflitos familiares, educação, suporte financeiro, drogas, influência de grupos, da vida comunitária e outros.

\subsection{Desestruturação Familiar}

A família desempenha um papel social relevante, tal premissa é tão revestida de veracidade que o legislador por compartilhar dessa mesma compreensão se preocupou em protegê-la, assim a $\mathrm{CF} / 88$ traz em seu texto especificamente no artigo 226 o princípio da integral proteção à família, reconhecendo que essa instituição contribui para o equilíbrio da sociedade, portanto, merece proteção do Estado.

Essa proteção dada à família pelo ente estatal decorre da importância da convivência familiar na formação do cidadão, pois, como afirma Trentin (2011), a prioridade garantida à criança e ao adolescente não é obrigação exclusiva do Estado e da sociedade, mas, sobretudo, da família, porque a vida, a saúde, o lar, a dedicação com amor são primordiais para o crescimento e o desenvolvimento do indivíduo. Portanto, a ausência de convivência familiar, a carência de amor e afeto comprometem o desenvolvimento da criança e do adolescente, em virtude de a família ser o agente socializador, por excelência, do ser humano, afinal a família transcende a qualquer partido político, associação ou qualquer outro gênero de agrupamento humano, pois sua constituição é feita por relações de compreensão e respeito.

Trentin (2011, p. 222) informa que "a família é o ambiente social onde o ser humano desenvolve os seus primeiros relacionamentos e é submetido às primeiras imposições de regras e limites, assim conflitos familiares interferem no comportamento dos membros da família com outras pessoas".

Assim, o desmembramento familiar, abandono, instabilidade residencial e o próprio comportamento desviante dos pais ou familiares, como prostituição, alcoolismo, drogas e violência, conduzem os adolescentes para um comportamento delitual.

Sob essa ótica, Gomide (2001, p. 39) apud Trentin (2011, p. 222) informa que crianças que têm "uma infância marcada por violência, podem perder a capacidade de constituir relações afetivas com os outros, e assim tendem a assumir uma postura violenta sem remorso", pois vínculos afetivos que sequer foram desenvolvidos com os pais, não poderão ser estendidos a terceiros estranhos.

Assis e Feijó (2004), corroborando com as informações até aqui apresentadas, afirmam que atitudes cruéis, violentas e negligentes dos pais; falta de supervisão ou controle; 
conflitos familiares; maus exemplos de conduta; falta de comunicação entre pais e filhos; carência afetiva; exclusão social e falta de educação e valores, são possíveis causas da delinquência juvenil decorrentes da desestruturação familiar, em especial quando se leva em consideração que a personalidade de um indivíduo é um misto de influências do meio com a bagagem genética individual.

Em suma, observa-se que a base familiar sustentada no bem comum, no respeito recíproco, afetividade, sem conflitos parentais e no respeito aos valores fundamentais propiciam condições efetivas ao adolescente de se desenvolver e tornar-se um adulto responsável e atuante na sociedade, diminuindo as possibilidades de marginalizar-se e vir a delinquir.

\subsection{Exclusão Social}

A exclusão social sempre foi alvo frequente de debates, de modo que a tentativa de encontrar soluções que a equilibrem e a controlem é sempre um tema atual. Incialmente, conforme afirmam Da Costa e Porto (2006, p. 243), “a exclusão social não é sinônimo de violência ou delinquência, mas implicitamente, ela pode contribuir para o seu desenvolvimento e, de certa forma, pode desencadear a criminalidade".

Para Assis e Feijó (2004), a ideia de exclusão social assinala um estado de carência ou privação material, de segregação, de discriminação, de vulnerabilidade em alguma esfera, isto é, a exclusão, associa-se a um processo de desvinculação social, já que o excluído não escolhe a sua condição, ela se dá numa evolução temporal, como resultado das mudanças da sociedade.

Para Porto (2000), a exclusão social, traz consigo consequências como o desemprego, a falta de alimento, de acesso a serviços de saúde, educação, de moradia adequada, de recursos que impossibilitam o exercício da dignidade humana. Desse modo, a autora afirma que a exclusão social tem sido uma categoria importante e presente nas análises que buscam relacionar violência e direitos civis, pois a delinquência se faz mais presente nas zonas que possuem necessidades sociais, confirmando o fato de que os excluídos de direitos tornam-se alvos ou atores mais imediatos da violência.

A adolescência, por ser uma etapa de desenvolvimento, o indivíduo está vulnerável a comportamento de risco, sobretudo, por esta ser uma fase de experimentação e de busca de identidade. Desse modo, Assis e Feijó (2004) afirmam que aliada a esses conflitos internos e externos, próprios da adolescência, o jovem ainda vivencia uma situação de exclusão social, 
em especial por motivos de ordem econômica, sua relação com o meio pode se tornar frágil e desafetuosa, podendo resultar em um desencadeamento de comportamentos de revolta e até mesmo de banalização da violência.

Não se afirma com essa premissa que pobreza é uma das causas direta da delinquência, pois, como afirma Panucci (2005, p. 46), "a pobreza não é indicador do aumento da criminalidade, mas a desigualdade social sim". Prova disso, segundo a autora, são os maiores índices de violência no Brasil pertencerem aos Estados, como São Paulo e Rio de Janeiro, que apesar de serem ricos possuem uma desigual distribuição de renda.

A prática de condutas ilícitas para suprir necessidades financeiras é injustificável e, quando praticada por adolescentes, eleva a sociedade a um estado de caos social, todavia, conforme expõe Panucci (2005, p. 47), tal situação "é reflexo de uma sociedade que adota a postura em que o ter é superior ao ser”. Assim, o poder, a renda alta, a possibilidade de consumo de uma pequena parcela da população geram insatisfação nos indivíduos que fazem parte da camada mais pobre.

Assis e Feijó (2004) destacam que na adolescência o jovem sente a necessidade de fazer parte de grupos, para se sentir aceito e pertencente a um meio social. Essa situação, em alguns casos, leva o jovem ao consumismo e a comportamentos não condizentes com sua realidade econômica. Para as autoras, a valorização dos objetos simbólicos, que exaltam o consumo e indicam o status, como carros, roupas, equipamentos eletrônicos, tênis e outros, provocam uma frustração crescente em jovens pertencentes à massa excluída, em especial, quando essa situação é polarizada pela coexistência de uma oligarquia riquíssima.

Assim, observa-se que o fator socioeconômico, dada à má distribuição de riquezas e as desigualdades sociais, possuem uma estreita relação com o aumento da criminalidade, induzindo o adolescente excluído socialmente à delinquência, entretanto esse fato é intensificado quando aliado a essa situação, há também um desvirtuamento dos valores morais, éticos e uma exacerbação do consumismo, pois a pobreza isolada, não é causa direta de desvios de conduta, o combustível para a violência é o abandono social.

\subsection{Envolvimento com Drogas}

As drogas ganham papel de destaque no cenário do estudo das causas da delinquência juvenil. Para Abramovay (2003, p. 47) apud Santana (2006, p. 20), o início do consumo de drogas por adolescentes "é favorecido pela pressão do grupo e pela 
vulnerabilidade a influência dos colegas, associada à insegurança típica da idade e necessidade de aceitação".

O fato da adolescência, de acordo com Marques e Cruz (2000), ser uma etapa em que o jovem não aceita orientações, por estar testando a possibilidade de ser adulto, de ter o poder e controle sobre si mesmo, ele se afasta da família e adere a grupos de iguais. Se ele pertencer a um grupo onde haja contato com as drogas, ele estará vulnerável ao consumo.

Já para Agostini (2003, p. 48) apud Santana (2006, p. 20), um dos "fatores responsáveis pelo aumento da criminalidade juvenil é o tráfico de drogas que, nas grandes cidades, está relacionado ainda ao crescimento da violência e das disputas entre quadrilhas do crime organizado".

Santana (2006) destaca que o envolvimento de adolescentes com entorpecentes é uma das causas mais relevantes da delinquência entre menores, visto que, depois de se tornar dependente, o adolescente depara-se com a necessidade de manter o vício e, para isto, torna-se capaz de cometer as piores atrocidades contra a vida humana.

Corroborando com essas informações, Panucci (2005) afirma que no desejo invencível de consumir a droga, grande parte dos usuários se veem na necessidade de traficar ou praticar delitos contra o patrimônio, pois o indivíduo precisa da droga e, como não tem dinheiro, o único meio que encontra para consegui-la é traficando, furtando ou roubando. A autora expõe que esse é um dos motivos que confirmam a droga como um fator para a criminalidade, pois de um simples usuário, o jovem torna-se praticante de infrações penais, em virtude da manutenção do vício.

Em suma, seja por rebeldia, abandono, pobreza, violência, curiosidade, pressão de colegas, o fato é que o envolvimento do adolescente com drogas em algum momento lhe causará algum dano, seja mental, físico, moral ou social, pois em um determinado instante, esse jovem dependente será induzido, pela necessidade de saciar o vício, a praticar algum delito, em algum momento, o vício irá corrompê-lo, de maneira que comportamentos violentos passarão a ser vistos como um fenômeno comum e a delinquência nada mais será do que um meio de suprir a necessidade do consumo de drogas.

\subsection{Inimputabilidade Penal}

A legislação não definiu expressamente o que vem a ser imputabilidade, mas seu conceito está implícito e pode ser extraído do artigo 26 do Código Penal Brasileiro, que elencou os casos de inimputabilidade. 
Art. 26. É isento de pena o agente que, por doença mental ou desenvolvimento incompleto ou retardado, era, ao tempo da ação ou da omissão, inteiramente incapaz de entender o caráter ilícito do fato ou de determinar-se de acordo com esse entendimento.

Desse modo, sobre as excludentes de culpabilidade, Bitencourt (2009, p. 379) esclarece que são "conhecidos na doutrina três sistemas definidores dos critérios fixadores da inimputabilidade ou culpabilidade diminuída: o biológico; o psicológico e o biopsicológico". Segundo o autor, o primeiro condiciona a responsabilidade à saúde mental, à normalidade da mente. Já o psicológico declara a irresponsabilidade se, ao tempo do crime, estava abolida no agente a faculdade de apreciar a criminalidade do fato e determinar-se de acordo com essa apreciação. E o método biopscicológico reúne os dois métodos citados, ou seja, a responsabilidade só será excluída se o agente, em razão de enfermidade ou retardamento mental, era, no momento da ação, incapaz de entendimento ético-jurídico e de autodeterminação.

Bitencourt (2009) declara que o Direito Penal brasileiro adota, como regra geral, o sistema biopsicológico e, como exceção, o sistema puramente biológico para as hipóteses dos menores de dezoito anos, conforme prevê os artigos 228 da CF/88 e artigo 27 do CP, pelos quais, os sujeitos com idade penal incompleta, que praticarem infrações, serão submetidos às normas estabelecidas em legislação especial, no caso, o ECA.

Assim, a imputabilidade por presunção legal só se inicia aos dezoito anos, de modo que, como assinala Bitencourt (2009), ao adotar o sistema biológico para definir a maioridade penal, a legislação brasileira ignora o desenvolvimento mental do menor, considerando-o inimputável, independentemente de possuir plena capacidade de entender a ilicitude do fato ou de determinar-se segundo esse entendimento.

Nesse sentido, acerca da questão da culpabilidade penal do adolescente infrator, existe muita divergência doutrinária, pois a absoluta inimputabilidade do menor de dezoito anos estabelece que o mesmo não é capaz de entender as normas da vida social e de agir conforme este entendimento. Todavia, Santana (2006) relata que, para alguns doutrinadores, nos dias atuais, predomina um acelerado processo de comunicação, de forma que não há motivo por que desconsiderar a precocidade de consciência delitual do adolescente, pois o mesmo tem condições de conhecer o caráter ilícito das infrações, portanto deveria responder criminalmente pelos seus atos. Essa corrente defende ainda a redução da maioridade penal para dezesseis anos, já que, com essa idade o adolescente tem capacidade mental para 
escolher seus representantes através do voto, poderá também ter consciência do caráter ilícito das suas ações.

Ainda sob essa ótica, Adorno, Bordini e Lima (1999) afirmam que a inimputabilidade é uma das possíveis causas do aumento de crimes cometidos por adolescentes. Para os autores, muitos jovens utilizam a legislação de proteção aos direitos da criança e do adolescente como uma mácula para a transgressão das condutas e adoção de comportamentos violentos, pois, a inimputabilidade passa a ideia errônea de impunidade. Os autores afirmam ainda:

Desde sua edição, o ECA vem sendo objeto de ampla polêmica. Para alguns, é visto como instrumento eficaz de proteção e de controle social. Em posição diametralmente oposta, encontram-se aqueles que suspeitam ser o ECA instrumento legal inaplicável à sociedade brasileira, pois, segundo seus argumentos, a criminalidade juvenil vem crescendo porque os jovens delinquentes não são punidos ou, quando o são, as medidas socioeducativas são brandas comparativamente à gravidade das ocorrências policiais.

Favoravelmente à inimputabilidade dos adolescentes, Bitencourt (2009, p.381) afirma que, "com a redução da menoridade penal explodiremos a capacidade das penitenciárias já superlotadas e somente teremos bandidos mais jovens, delinquindo por mais tempo". Para o autor, com a perda da inimputabilidade, os jovens irão fazer o aperfeiçoamento na delinquência no interior das prisões, pois, o sistema penitenciário não oferece as condições necessárias para ressocialização dos adultos, muito menos, oferecerá para a dos adolescentes.

Contrariamente a essa ideia, Santana (2006) afirma que, apesar do legislador entender que o peculiar estado de desenvolvimento psicossocial dos adolescentes não os torna aptos a punições de suas ações como os imputáveis, é notório que o mundo evoluiu e que as crianças e jovens, cada vez mais precoces, têm acesso a informações e experiências que antes eram restritas apenas aos adultos e tal fato lhes concede atingir um grau de desenvolvimento mental muito antes do que prega a lei, de forma que os jovens infratores gozam de uma situação relativamente privilegiada quando praticam um ato criminoso, visto que a legislação os vê como vítimas e não como agressores.

Sob esta ótica, Ferreira (2001, p. 14) apud Sírio (2009, p. 37) afirma que tal situação evidencia que "as sanções impostas pelo ECA são tolerantes e não intimidam os que pretendem transgredir a lei, transformando a inimputabilidade dos jovens numa alternativa para o ingresso na criminalidade". 
Desse modo, independente das posições doutrinárias acerca da inimputabilidade dos jovens, a redução da maioridade penal não resolveria o problema da delinquência juvenil, pois encarcerar adolescentes em um sistema penitenciário sucateado como o brasileiro, apenas agravaria o problema. Entretanto, é preciso considerar que a não imputação penal dada ao adolescente pela legislação, pode ser um fator de estímulo, aliciamento ou indução de jovens vulneráveis ou de má-fé à marginalização, pois é inegável que os delinquentes juvenis são responsáveis por graves problemas sociais, sendo muitas vezes indivíduos, violentos e assustadores, apesar de ser, conforme a legislação, pessoas em desenvolvimento.

\section{ANÁLISE DAS ESTATÍSTICAS DA CRIMINALIDADE JUVENIL NA CIDADE DE TERESINA - PIAUÍ}

A fim de analisar os aspectos inerentes ao envolvimento do adolescente da cidade de Teresina na criminalidade, realizou-se uma pesquisa de campo feita através de dados disponibilizados pela Delegacia Geral da Polícia Civil do Estado do Piauí sobre as ocorrências policiais em que houve participação de menores de dezoito anos.

As informações prestadas pela Delegacia Geral são decorrentes dos relatórios das ocorrências criminais registradas em todas as delegacias especializadas da capital piauiense, entre os anos de 2009 a 2012. Para o estudo em questão, foram levados em consideração os dados das delegacias especializadas da Criança e do Adolescente, isto é, a Delegacia de Proteção à Criança e ao Adolescente - DPCA e a Delegacia de Segurança e Proteção ao Menor - DSPM, ambas com circunscrição em toda a capital e incumbidas de registrar e apurar, respectivamente, as ocorrências cometidas contra e por menores de dezoito anos.

Desse modo, ao tabular as estatísticas da DSPM entre os anos de 2009 a 2012, apurou-se a quantidade de 3.885 (três mil oitocentos e oitenta e cinco) registros de ocorrências policiais de infrações cometidas por menores de idade, conforme está demonstrado na Tabela 1. 


\begin{tabular}{|l|r|r|r|r|r|r|r|r|r|r|r|r|r|}
\hline & Jan. & Fev. & Maç. & Abr. & Mai. & Jun. & Jul. & Ago. & Set. & Out. & Nov. & Dez. & Total \\
\hline $\mathbf{2 0 0 9}$ & 103 & 55 & 120 & 103 & 97 & 91 & 72 & 102 & 100 & 70 & 116 & 56 & $\mathbf{1 0 8 5}$ \\
\hline $\mathbf{2 0 1 0}$ & 90 & 44 & 124 & 120 & 108 & 96 & 95 & 115 & 74 & 30 & 83 & 62 & $\mathbf{1 0 4 1}$ \\
\hline $\mathbf{2 0 1 1}$ & 99 & 100 & 81 & 43 & 98 & 100 & 83 & 115 & 73 & 29 & 83 & 47 & $\mathbf{9 5 1}$ \\
\hline $\mathbf{2 0 1 2}$ & 52 & 76 & 85 & 73 & 85 & 67 & 59 & 56 & 64 & 56 & 71 & 64 & $\mathbf{8 0 8}$ \\
\hline
\end{tabular}

Tabela 1. Número geral das ocorrências registradas na DSPM entre os anos de 2009 a 2012 na cidade de Teresina - Piauí.

Fonte: Estatísticas da Delegacia Geral da Polícia Civil do Estado do Piauí, 2013.

Observa-se, a partir dos dados apresentados na tabela 1, que os meses com maior quantidade de registro foram março, maio e agosto. Além disso, é possível verificar uma escala decrescente entre a quantidade anual das ocorrências registradas na DSPM entre os anos de 2009 a 2012, conforme está demostrado no Gráfico 1.

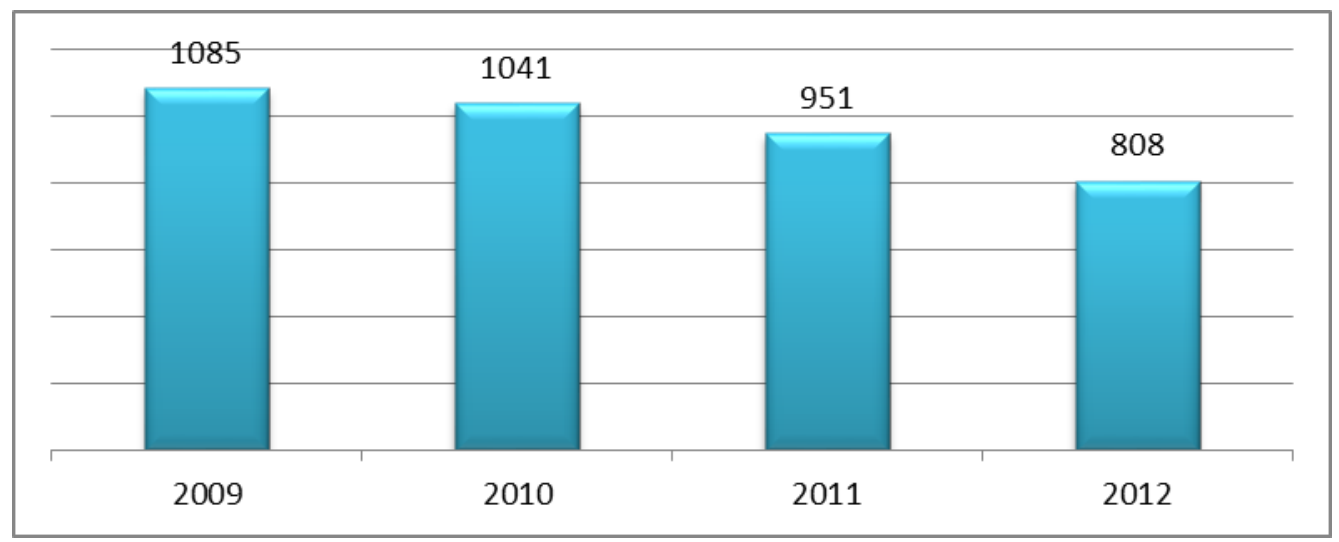

Gráfico 1. Quantidade anual das ocorrências registradas na DSPM entre os anos de 2009 a 2012.

Fonte: Estatísticas da Delegacia Geral da Polícia Civil do Estado do Piauí, 2013.

No Gráfico 2 é apresentada uma seleção de infrações que, segundo as estatísticas da Delegacia Geral da Polícia Civil, são as praticadas com maior habitualidade pelos adolescentes na capital piauiense. 


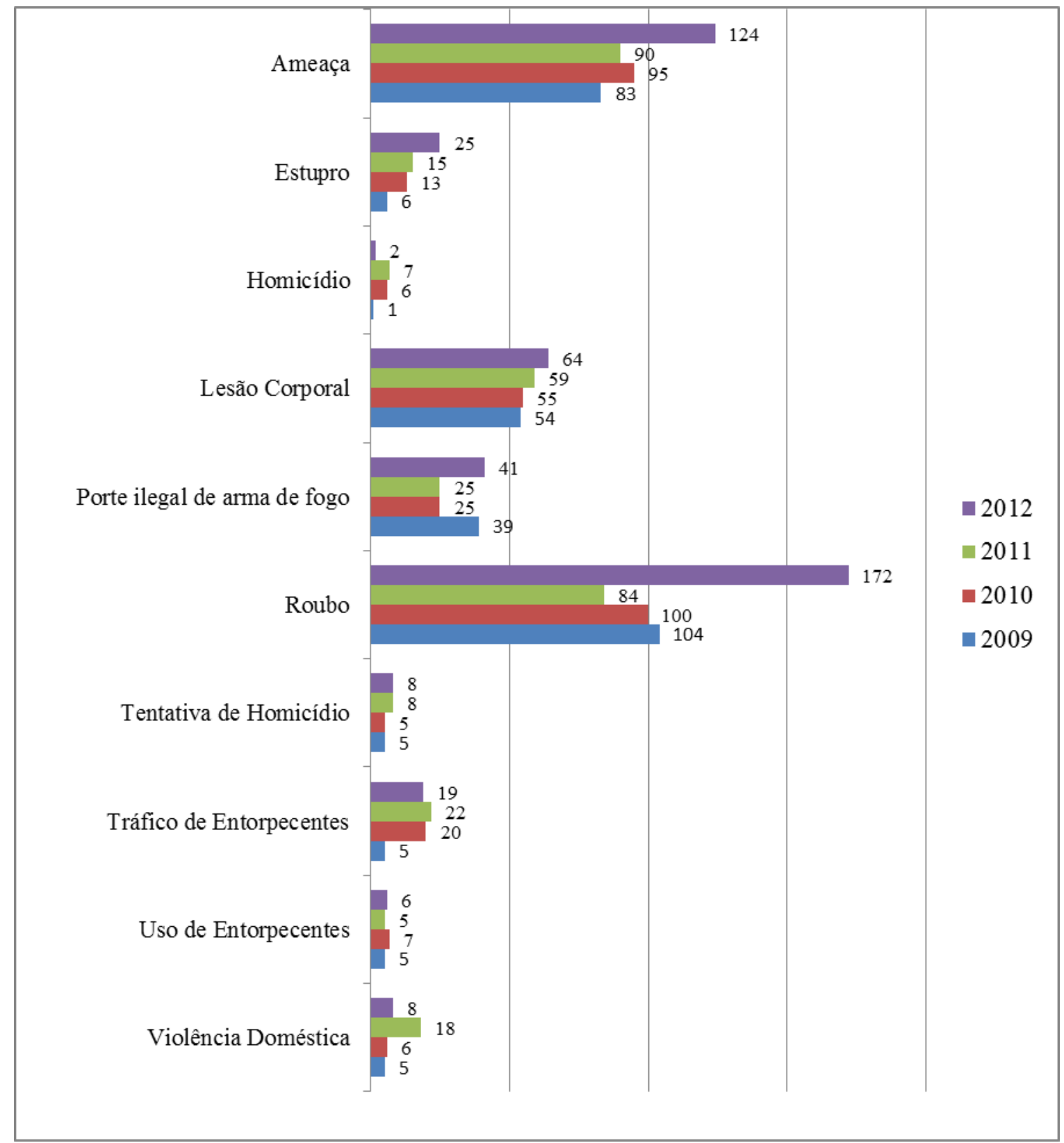

Gráfico 2. Aumento das infrações de maior potencial ofensivo

Fonte: Estatísticas da Delegacia Geral da Polícia Civil do Estado do Piauí, 2013.

Observa-se ainda, a partir do Gráfico 2, que as infrações com maior índice de frequência correspondem aos tipos penais com maior grau de ofensividade e, apesar desse fato, tais infrações tiveram um aumento considerável no período entre 2009 e 2012,

Ao analisar as infrações com maior frequência de registros, observa-se que à medida que aumentou o número de Boletins de Ocorrência - BO, referentes à infração de roubo, aumentaram também os registros de ocorrência por porte ilegal de arma de fogo, conforme apresenta Gráfico 3. 


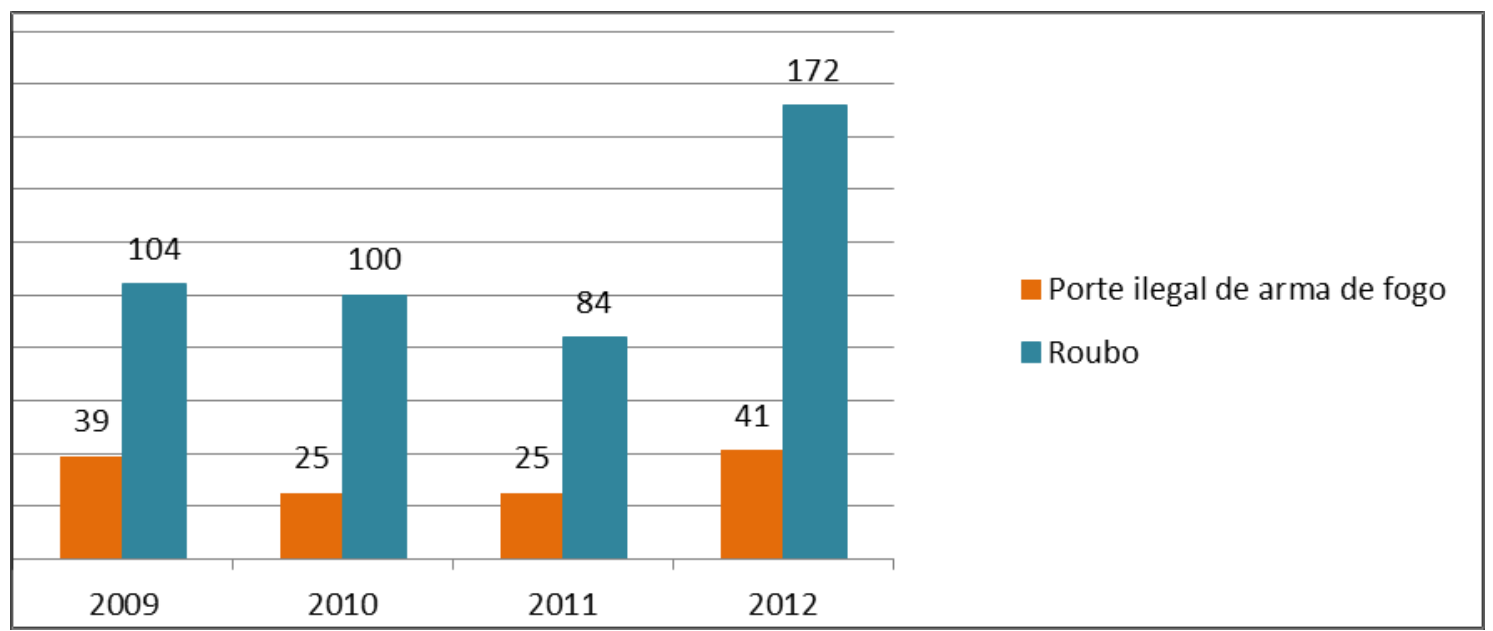

Gráfico 3. Relação entre as infrações Porte ilegal de arma de fogo e Roubo entre os anos de 2009 a 2012.

Fonte: Estatísticas da Delegacia Geral da Polícia Civil do Estado do Piauí, 2013.

Outra observação importante na análise das estatísticas se refere ao aumento do envolvimento de adolescentes com drogas. Os dados se tornam mais significativos quando se compara a totalidade das ocorrências policiais de tráfico de entorpecentes de todas as delegacias especializadas da capital, com as registradas na DSPM entre os anos de 2009 e 2012, conforme Tabela 3 demonstra.

\begin{tabular}{|c|c|c|c|}
\hline & $\begin{array}{c}\text { Registros de Tráfico de } \\
\text { Entorpecentes } \\
\text { (GERAL) }\end{array}$ & $\begin{array}{c}\text { Registros de Tráfico de } \\
\text { Entorpecentes (DSPM) }\end{array}$ & $\begin{array}{c}\text { Percentual de } \\
\text { participação dos menores } \\
\text { em tráfico de } \\
\text { entorpecentes }\end{array}$ \\
\hline 2009 & 52 & 5 & $9,62 \%$ \\
\hline 2010 & 110 & 20 & $18,18 \%$ \\
\hline 2011 & 168 & 22 & $13,10 \%$ \\
\hline 2012 & 146 & 19 & $13,01 \%$ \\
\hline
\end{tabular}

Tabela 3. Relação percentual das ocorrências de tráfico de entorpecentes registradas na DSPM e nas outras delegacias especializadas entre os anos de 2009 a 2012.

Fonte: Estatísticas da Delegacia Geral da Polícia Civil do Estado do Piauí, 2013.

E como última análise das estatísticas, verificou-se o grau de violência e a condição familiar dos adolescentes em situação de risco da cidade de Teresina. Constatou-se a partir dos dados da DSPM e da DPCA que houve um aumento nas infrações penais de ameaça, estupro e violência doméstica.

Com relação à infração de ameaça, o aumento representa um crescimento $12,7 \%$ entre os anos de 2009 e 2010, uma redução de 4,2\% entre os anos de 2010 e 2011, e um aumento de 26,6\% entre os anos de 2011 e 2012, totalizando, conforme Tabela 2, 393 
(trezentos e noventa e três) ocorrências de ameaças praticadas por adolescentes entre os anos de 2009 a 2012.

Sobre as infrações de estupro e violência doméstica, verifica-se um aumento progressivo dessas infrações, conforme os dados da Tabela 4.

\begin{tabular}{|c|c|c|c|c|}
\hline \multirow{2}{*}{} & \multicolumn{2}{|c|}{ ESTUPRO } & \multicolumn{2}{c|}{ VIOLÊNCIA DOMÉSTICA } \\
\cline { 2 - 5 } & $\begin{array}{c}\text { DPCA } \\
\text { (menor vítima) }\end{array}$ & $\begin{array}{c}\text { DSPM } \\
\text { (menor infrator) }\end{array}$ & $\begin{array}{c}\text { DPCA } \\
\text { (menor vítima) }\end{array}$ & $\begin{array}{c}\text { DSPM } \\
\text { (menor infrator) }\end{array}$ \\
\hline $\mathbf{2 0 0 9}$ & 57 & 6 & 50 & 5 \\
\hline $\mathbf{2 0 1 0}$ & 102 & 13 & 65 & 6 \\
\hline $\mathbf{2 0 1 1}$ & 60 & 15 & 46 & 18 \\
\hline $\mathbf{2 0 1 2}$ & 98 & 25 & 22 & 8 \\
\hline TOTAL & 317 & 59 & 183 & 37 \\
\hline
\end{tabular}

Tabela 4. Relação das ocorrências de estupro e violência doméstica na DPCA e DSPM na cidade de Teresina entre os anos de 2009 a 2012.

Fonte: Estatísticas da Delegacia Geral da Polícia Civil do Estado do Piauí, 2013.

Com a análise da Tabela 4, observa-se um aumento proporcional dos BO's de estupro e violência doméstica, tanto na DSPM quanto na DPCA, o que significa que o envolvimento de menores nesses dois tipos penais tem aumentado de maneira significativa, seja o adolescente como autor ou como vítima.

Constatou-se ainda que as infrações de ameaça, de estupro e violência doméstica cometidas por adolescentes aumentaram no decorrer do período citado e que o estupro teve um aumento de mais de $200 \%$ de 2009 a 2012. Em contrapartida se verifica que na capital piauiense existe um número razoável de violência sexual praticada contra crianças e adolescentes, de maneira que no período citado ocorreram 183 registros de violência doméstica e 317 registros de estupro contra vulnerável.

\section{CONSIDERAÇÕES FINAIS}

Diante do exposto, verifica-se que na cidade de Teresina, entre os anos de 2009 a 2012, com fulcro nos dados da Delegacia Geral da Polícia Civil do Estado do Piauí, houve uma redução progressiva da apreensão de crianças e adolescentes. Todavia, à medida que o número geral de apreensões diminuiu, aumentou consideravelmente o percentual da participação de adolescentes em crimes com maior potencial ofensivo como ameaça, estupro, porte ilegal de arma de fogo, roubo, homicídio tráfico de entorpecentes e violência doméstica. 
Tal premissa traz a evidência de que, na cidade de Teresina, estatisticamente, na DSPM houve uma diminuição do número geral de ocorrências criminais, entretanto, nos crimes violentos, contra a vida e o patrimônio, o número de Boletins de Ocorrência aumentou, o que significa que os adolescentes infratores na capital piauiense, estão delinquindo menos, em contrapartida, estão mais violentos e perigosos.

Ainda sobre essa premissa, observa-se que ela pode ter relação direta com o fato da brandura das medidas socioeducativas, pois uma punição leve dá a impressão de impunidade e permissividade para a prática de outras infrações. Isso se confirma na relação entre o número de apreensões de crianças e adolescentes e o aumento dos crimes contra a vida e o patrimônio, pois é sabido que na apreensão a autoridade policial, após a oitiva dos presentes, libera o menor aos seus responsáveis, sem qualquer sanção mais severa.

Assim, em 2009, o número de apreensões na DSPM foi de 568 menores e em 2012 foi de 276, porém, aumentou progressivamente o número de homicídios, roubos e porte ilegal de armas de 2009 a 2012, o que significa que o jovem que em 2009 foi apreendido e liberado sem nenhum ônus, provavelmente seja o mesmo que esteja, roubando, matando e ameaçando em 2012.

Outra observação relevante é referente ao aumento dos crimes contra o patrimônio, em especial o roubo, pois tal infração foi a mais cometida pelos adolescentes, foram 476 roubos entre os anos de 2009 a 2012. Paralelo ao crime de roubo está o aumento do crime de porte ilegal de arma de fogo, fato que possivelmente evidencia a relação do uso da arma para cometimento do roubo.

Verifica-se também o aumento dos crimes de tráfico de drogas e o uso de entorpecentes, de maneira que ambos se correlacionam, já que corriqueiramente o adolescente entra para o tráfico como meio de manter seu vício. Em relação ao aumento da agressividade do adolescente infrator de Teresina, verifica-se que ela pode estar ligada a reflexos de desajustes familiares, pois o número de estupros, agressões domésticas e ameaças praticadas por adolescentes em Teresina, no período estudado, é diretamente proporcional aos sofridos pelos menores, fato que converge para a teoria estudada, que afirma que crianças com uma infância marcada pelo abandono e pela violência tendem a desenvolver uma postura agressiva, sem vínculos afetivos com o próximo.

Dessa forma, verifica-se que o envolvimento de adolescentes com a criminalidade decorre não de uma causa específica e isolada, mas sim de causas multifatoriais, que envolvem fatores de cunho social, drogas, desajustes familiares e aplicação de medidas socioeducativas ternas. Assim, conclui-se ser necessário organizar uma estrutura capaz de 
atingir a criminalidade antes de sua existência, com educação, assistência social e apoio familiar e, aos menores já infratores, é preciso garantir meios para sua recuperação social e moral e penalidades condizentes com a infração cometida, que traduzam a resposta do Estado à sua conduta infracional.

\section{REFERÊNCIAS}

ADORNO, Sérgio; BORDONI, Eliana B. T; LIMA, Renato Sérgio. $O$ adolescente $e$ as mudanças na criminalidade urbana. São Paulo: São Paulo em perspectiva, v. 13, n. 4, p. 6274, 1999. Disponível em: <www.scielo.br/scielo.php?pid=S0102-88391999000400007>. Acesso em: 23 de Ago. 2012.

ASSIS, Simone Gonçalves de; FEIJÓ, Maria Cristina. O contexto de exclusão social e de vulnerabilidades de jovens infratores e de suas famílias. Estudos de Psicologia, v.9, p.157166, 2004. Disponível em: <http://www.scielo.br/pdf/epsic/v9n1/22391.pdf>Acesso em: 12 de Ago. 2012.

BITENCOURT, Cezar Roberto. Tratado de Direito Penal: Parte Geral. 14. ed. São Paulo: Saraiva, 2009. p. 106-381.

BRASIL. Constituição da República Federativa do Brasil. Promulgada em 5 de outubro de 1988. Vade Mecum Saraiva. 11. ed. São Paulo: Saraiva, 2011.

Decreto - Lei $\mathrm{n}^{\circ}$ 2.848, de 7 de dezembro de 1940. Dispõe sobre o Código Penal Brasileiro. Vade Mecum Saraiva. 11. ed. São Paulo: Saraiva, 2011.

Decreto - Lei n ${ }^{\circ} 3914$, de 9 de dezembro de 1941. Dispõe sobre a Lei de introdução ao Código Penal e da Lei de Contravenções Penais. Vade Mecum Saraiva. 11. ed. São Paulo: Saraiva, 2011.

Lei $\mathrm{n}^{\circ} 8.069$, de 13 de julho de 1990. Dispõe sobre o Estatuto da Criança e do Adolescente e dá outras providencias. Vade Mecum Saraiva. 11. ed. São Paulo: Saraiva, 2011.

CUNHA, Rogério Sanches; LEPORE, Paulo Eduardo; ROSSATO, Luciano Alves. Estatuto da Criança e do Adolescente comentado. 2. ed. São Paulo: Revista dos Tribunais, 2011.

DA COSTA, Marli MM; PORTO, Rosane TC. Exclusão social, violência estrutural e delinquência juvenil: uma análise a partir de Michel Foucault. Revista Direito e Justiça: Reflexões Sociológicas, v. 1, n. 9, p. 243-266, 2006.

D’ANDREA, Giuliano. Noções de Direito da Criança e do Adolescente. Florianópolis: $\mathrm{OAB} / \mathrm{SC}, 2005$. 
DELEGACIA GERAL DA POLICIA CIVIL DO ESTADO DO PIAUI. Estatísticas das Ocorrências Policiais das Delegacias Especializadas de Teresina - 2009 a 2010. Teresina: Gerência de Pesquisas e Estatísticas, 2013.

MARQUES, Ana Cecília P. Rosselli; CRUZ, Marcelo S. O adolescente e o uso de drogas. São Paulo: Revista Brasileira de Psiquiatria. v. 22. s. 2. Dec. 2000. Disponível em:< www.scielo.br/scielo.php?script=sci_arttext\&pid=S1516>. Acesso em: 12 de Ago. 2012.

NEIS, Camila. Fatores da Criminalidade: Um estudo sobre a influência dos fatores sociais na prática de infrações penais. Trabalho de Conclusão de Curso (Direito) - Universidade do Vale do Itajaí. Biguaçu, SC, 2008. Disponível em: < http://siaibib01.univali.br/pdf/Camila\%20Neis.pdf> Acesso em: 20 de Set. 2012.

PANUCCI, Laís Flávia Arfeli. Aumento da Criminalidade: causas. São Paulo: Intermas, 2004. 9 v. disponível em:<http://intertemas.unitoledo.br/revista/index.php/Juridica/258>. Acesso em: 10 de Ago. 2012.

SIRIO, Leandro dos Santos. Da inimputabilidade do menor relativamente incapaz. Trabalho de Conclusão de Curso (Direito). Universidade Vale do Rio Doce. Governador Valadares, MG, 2009. Disponível em: <http://pt.scribd.com/doc/76614201/Maioridade-Penal>. Acesso em: 13 de Set. 2012.

TRETIN, Ângela Correia. Adolescentes em conflito com a lei e com a família: Um estudo interdisciplinar. Congresso Internacional de Ciências Criminais. PUC - RS. Ed.11, 2011. Disponível em: <ebooks.pucrs.br/edipucrs/anais/cienciascriminais/edicao2/Angela>. Acesso em: 12 de Ago. 2012.

SANTANA, Regiane Maria. Adolescente infrator: uma questão jurídica ou uma questão social. Trabalho de Conclusão de Curso (Direito) - Universidade do Vale do Itajaí - Univale. Biguaçu, SC, 2006. Disponível em: <siaibib01.univali.br/pdf/Regiane\%20Maria > Acesso em: 12 de Ago. 2012. 